$11-2008$

\title{
Moving Ahead: Five Essential Elements for Working Effectively With Girls
}

\author{
Betsy Mattews \\ Eastern Kentucky University \\ Dana Jones Hubbard \\ Cleveland State University, d.j.hubbard@csuohio.edu
}

Follow this and additional works at: https://engagedscholarship.csuohio.edu/clsoc_crim_facpub

Part of the Criminology Commons, Gender and Sexuality Commons, and the Social Control, Law, Crime, and Deviance Commons

How does access to this work benefit you? Let us know!

Publisher's Statement

(c) 2008 Elsevier

\section{Original Citation}

Matthews, B., \& Hubbard, D. J. (2008). Moving ahead: Five essential elements for working effectively with girls. Journal of Criminal Justice, 36(6), 494-502. doi:10.1016/j.jcrimjus.2008.09.011

\section{Repository Citation}

Mattews, Betsy and Hubbard, Dana Jones, "Moving Ahead: Five Essential Elements for Working Effectively With Girls" (2008). Sociology \& Criminology Faculty Publications. 90.

https://engagedscholarship.csuohio.edu/clsoc_crim_facpub/90

This Article is brought to you for free and open access by the Sociology \& Criminology Department at EngagedScholarship@CSU. It has been accepted for inclusion in Sociology \& Criminology Faculty Publications by an authorized administrator of EngagedScholarship@CSU. For more information, please contact library.es@csuohio.edu. 


\title{
MOVING AHEAD: FIVE ESSENTIAL ELEMENTS FOR WORKING EFFECTIVELY WITH GIRLS
}

\author{
Betsy Matthews, Eastern Kentucky University \\ Dana Jones Hubbard, Cleveland State University
}

This article was originally published in:

Matthews, Betsy and Dana Jones Hubbard (2008) Moving Ahead: Five Essential Elements for Working Effectively with Girls. Journal of Criminal Justice, 36, 494-502.

Post-print standardized by MSL Academic Endeavors, the imprint of the Michael Schwartz Library at Cleveland State University, 2013

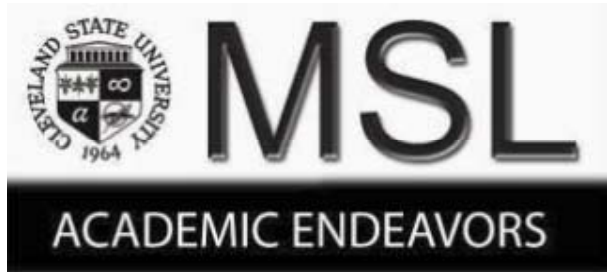




\title{
Moving ahead: Five essential elements for working effectively with girls
}

\author{
Betsy Matthews ${ }^{\mathrm{a}}$, Dana Jones Hubbard ${ }^{\mathrm{b}, *}$ \\ a Correctional and Juvenile Justice Studies, Eastern Kentucky University, Stratton 102, 521 Lancaster Avenue, Richmond, KY 40475, United States \\ ${ }^{\mathrm{b}}$ Department of Sociology, Cleveland State University, 2121 Euclid Avenue, RT 1728, Cleveland, OH 44115, United States
}

\section{A R T I C L E I N F O}

\section{Introduction}

With all the recent attention given to the development of effective gender-responsive programming for girls in the juvenile justice system, it was frustrating to turn on the national news and see a "finishing school" being touted as cutting edge programming for female delinquents (Hartman, 2006). Girls in a facility were being taught to boil potatoes and dance their way out of the delinquent lifestyle. Although this program, operated by the California Youth Authority, may not adequately represent other recent genderresponsive initiatives, the news piece serves as a stark reminder of how little progress has been made toward the development of effective, evidence-based programming for adolescent delinquent girls. This article first briefly considers the impediments to the development of effective girls' programming. Then, focusing on the last of these impediments, the gap between research and practice, provides concrete strategies for improving girls' programming in a manner that reflects the current state of knowledge regarding the delinquency and other problem behavior of girls.

\section{Statement of the problem: impediments to effective girls' programming}

There are four key impediments to effective girls' programming, the first of which is gender-stereotyped thinking. According to Marion Daniels, "for years people have assumed that all you have to do to make a program designed for boys work for girls is to paint the walls pink and take out the urinals" (as cited in Chesney-Lind, 2000, p. 139). This gender-stereotyped thinking has a long history in female institutions. Over recent decades, studies had revealed that not only

\footnotetext{
* Corresponding author. Tel.: +1 2166874508.

E-mail address: d.j.hubbard@csuohio.edu (D.J. Hubbard).
}

do institutionalized females have fewer opportunities for vocational training than males, but the programs offered are limited to cosmetology, clerical, and other service skills that are associated with underpaid and unstable jobs (Lahm, 2000; Morash, Haarr, \& Rucker, 1994; Rafter, 1995). The above referenced news story suggests that these common gender stereotypes continue to guide the thinking about what girls need to be successful in life.

A second impediment to effective girls' programming is rooted in numbers alone. For years, correctional and juvenile justice administrators have argued that the small numbers of female offenders do not warrant a big investment of resources (Belknap, 2001). Certainly this line of thinking limits the quantity and range of programming for girls. More importantly, perhaps, is the effect it has on the research and development required to support effective, gender-responsive programming. According to the Office of Juvenile Justice and Delinquency Prevention's (OJJDP) Girls' Study Group, progress toward effective girls' programming is being undermined by a lack of investment in evaluation (Zahn, 2006). As of November 2006, the Study Group had identified only eighteen evaluations of girls-only programs, and these evaluations were not of sufficient scientific rigor to permit definitive conclusions about "what works" for girls. This leaves juvenile justice administrators, whose funding for programs is increasingly dependent on their ability to demonstrate that a proposed program is evidence-based, in a state of quandary.

Third, because of a perceived increase in violence among girls, any additional resources are being used to place more formal controls on girls rather than to support the development of effective genderresponsive programs and services (Goodkind, 2005). According to official statistics, females accounted for 29 percent of total juvenile arrests, an increase of 35 percent since 1980 (Snyder \& Sickmund, 2006). Most of this increase was attributable to increases in arrests for assaults. A comprehensive analysis of official and self-report data on female delinquency led the OJJDP Girls' Study Group to conclude that the increases in official rates of girls' violent delinquency stem more 
from changes in the laws and the actions of officials rather than changes in the behavior of girls (Steffensmeier, Schwartz, \& Zhong, 2005). What were once considered normal fights between family members were now classified as assaults that attract formal police intervention and more frequently result in arrest (Chesney-Lind, 2003). Nonetheless, this increase in official rates of violence contributed to more arrests, formal sanctions, and incarceration for girls. Females now comprise 23 percent of offenders on juvenile probation (an increase of 14 percent since 1985), and 15 percent of the incarcerated juvenile population (an increase of 2 percent since 1999) (Snyder \& Sickmund, 2006). These larger numbers are harder to ignore, and have heightened the discourse about the need to invest in girls' programming.

The last, and perhaps largest, impediment to the improvement of girls' programming stems from the abstract nature of the principles promulgated by "gender-responsive" and "what works" scholars. The "gender-responsive" or "gender-specific" literature, rooted in a feminist perspective, emphasizes the unique experiences of being a girl in the United States and the different pathways to delinquency among boys and girls. The authors of this literature assert that girls need qualitatively different types of programs and services to adequately address their delinquent behavior (see for example, Belknap, 2001; Belknap \& Holsinger, 1998; Bloom, 2000; Bloom, Owen, \& Covington, 2003; Chesney-Lind, 1997). The "what works" literature, emanating from the work of Canadian psychologists, synthesizes quantitative research on correctional and juvenile justice programs and has promulgated principles of effective intervention that are associated with a reduction in recidivism (see for example, Andrews, Zinger, Bonta, Gendreau, \& Cullen, 1990; Cullen \& Gendreau, 2000; Latessa, Cullen, \& Gendreau, 2002; Lipsey \& Wilson, 1998; Sherman et al., 1997). These researchers assert that the strongest criminogenic needs (i.e., correlates of delinquency) are similar among boys and girls. Moreover, they assert that the evidence-based principles are applicable to males and females alike. Despite differences in philosophy, both the "gender-responsive" and "what works" scholars ${ }^{1}$ have contributed to a growing body of knowledge about what is needed to prevent girls' delinquency. ${ }^{2}$

How then, has this work impeded the development of effective girls programming? It is the authors' belief that although each group offers general principles for program development, neither does a sufficient job of providing concrete ways to transfer these principles and knowledge into programs for girls. For example, the "genderresponsive" group emphasizes the importance of developing relationships with girls but provides very little instruction on how to accomplish this. Similarly, as one of the key "what works" principles, the "responsivity principle" recognizes that girls, and other subgroups, require approaches that match their personal characteristics and learning styles, but says very little about specific ways to reflect this in practice.

This failure to transfer knowledge into practice may stem from the weakness of each body of literature. As reported above, the "genderresponsive" literature lacks empiricism, and therefore, is of limited utility to agencies wanting to implement evidence-based practice. In contrast, the gap between the knowledge emanating from the "what works" research and juvenile justice practice may stem from an over dependency on empiricism and inductive reasoning. This "what works" research agenda has focused, primarily, on the use of metaanalyses (i.e., quantitative syntheses of existing studies) to demonstrate the utility of rehabilitative programming and identify the characteristics of programs that produced the largest reduction in recidivism (see Andrews, Zinger, et al., 1990; Lipsey \& Cullen, 2007; Lipsey \& Wilson, 1998). This work is an invaluable source of "knowledge construction" for the corrections and juvenile justice fields (Cullen \& Gendreau, 2000, p. 133); it provides a solid empirical basis for the development of programs for offenders. Some, however, have argued that it lacks a strong conceptual or theoretical basis upon which to draw (Ward, Melser, \& Yates, 2007).
A look back to the early stages of the "what works" research agenda reveals Palmer (1995) cautioning against this very thing. Palmer warns correctional researchers and administrators against limiting program development to the inductive line of reasoning supported by metaanalysis. He argued that quantitative results must correspond with clear theoretical bases for rehabilitative programming. In a recent review of the empirical literature on rehabilitation, Lipsey and Cullen (2007) repeated this caution, calling for research that goes beyond measuring the main effect of treatment and is capable of clearly differentiating the characteristics of more and less effective programs; this type of research, they argued, will advance the theory development and conceptual analysis needed to bridge the gap between research and practice.

The remainder of this article represents an initial step toward bridging this gap between research and practice. It describes five essential elements, each of which reflect an integration of the empirical basis promulgated by the "what works" literature and the theoretical basis that is so well articulated in the "gender-responsive" literature. That is, these elements are firmly rooted in the current state of knowledge regarding effective girls' programming and are designed to provide a basis for program development that moves agencies toward effective, evidence-based programming for adolescent delinquent girls.

\section{Essential elements}

In the next sections of this article, the "gender-responsive" and "what works" literature are supplemented by the counseling literature and the literature on specific problem behaviors most relevant to girls (e.g., depression, eating disorders, risky sexual behavior). Rather than describing a "program," five elements are described that are believed to be essential to working with girls regardless of the context (i.e., community-based, institutional) or level of intervention (e.g., prevention, intervention). These five strategies include: (1) using a comprehensive and individualized assessment process, (2) building a helping alliance, (3) using a gender responsive cognitive-behavioral approach, (4) promoting healthy connections, and (5) recognizing within girl differences.

\section{Using assessment to guide program planning and evaluation}

The first essential element is a comprehensive assessment protocol. Assessment is the foundation for program planning and evaluation. It helps answer the questions "what are you trying to change, how will you do it, and how will you know when you succeed?" Additionally, a comprehensive assessment protocol will facilitate further research on factors that contribute to girls' delinquency and enhance the knowledge about girls' unique needs.

Although both groups of scholars agree on the importance of a comprehensive assessment protocol for girls, they have different views about what that protocol should include. The "what works" researchers are clear in saying that a structured, objective, quantitative risk/ need assessment is necessary for estimating youths' likelihood of reoffending, regardless of gender (Andrews, Bonta, \& Hoge, 1990; Lowenkamp \& Latessa, 2004). They further suggest that the identified risk category should be used as the basis of program placement, with higher risk youth being placed in more intensive and secure settings. The gender-responsive researchers take issue with both points. First, they assert that existing risk assessment tools have been developed based on male populations, and thus, do not adequately measure factors unique to girls' delinquency (Covington \& Bloom, 2003; Hannah-Moffat, 1999). Second, they refute the idea that girls are high "risk" and in need of secure settings; rather, they argue that girls are high "need," present more danger to themselves than others, and can best be served through treatment provided in the community (Bloom, 2000; Covington \& Bloom, 2003; Hannah-Moffat \& Shaw, 2003). On the basis of these two points, the gender-responsive group prefers a 
qualitative, interview-based assessment that taps into the female experience.

Based on what is known about the correlates of crime and girls' unique needs, the following assessment protocol is recommended for female offenders.

1. Measure girls' risk of recidivism through the use of a validated, actuarial risk assessment instrument. Proper treatment matching is dependent on knowing youths' risk of recidivism. The research indicates that actuarial risk assessment instruments that include factors known to be associated with recidivism are more effective than clinical approaches at predicting recidivism (Andrews \& Bonta, 1999; Gottfredson, 1987; Jones, 1996). Moreover, recent studies had found actuarial instruments to predict the recidivism of males and females equally well (Flores, Travis, \& Latessa, 2004; Ilacqua, Coulson, Lombardo, \& Nutbrown, 1999; Schwalbe, Fraser, Day, \& Arnold, 2004). If used appropriately, these instruments guard against harmful over classification of girls by ensuring that intensive services and supervision are reserved for the highest risk girls.

Based on a review of three hundred risk assessment instruments, OJJDP's Girls' Study Group has identified two general risk assessment instruments that appear appropriate for female populations (Brumbaugh \& Hardison, 2006). The Youthful Level of Services/Case Management Inventory (YLS/CMI) (Hoge \& Andrews, 2002) and the Early Assessment Risk List for Girls (Earl-21G) (Levene et al., 2001) have been validated with samples of delinquent girls. Both of these instruments include dynamic risk factors that are among some of the strongest correlates of crime (e.g., family, peers, antisocial attitudes); they provide a basis for case planning and allow for reassessment as a means of measuring change in treatment targets.

2. Conduct other standardized, objective measures of problem areas known to be prevalent among girls. There are several factors that commonly underlie or precede girls' delinquency including depression, eating disorders, suicide, relational aggression, selfmutilation, victimization, and risky sexual behavior (Covington \& Bloom, 1999). Thus, in addition to assessing and targeting those criminogenic needs that may be most proximate to a girl's delinquent behavior, it is essential to assess and address these factors (Lowenkamp \& Latessa, 2002). They are important responsivity factors that, if left unaddressed, will interfere with girls' amenability to treatment. Objective methods of measurement can be used to document the level of the problem within the individual and among the population of girls served, and that can be used to measure change. Some possible instruments include the Beck Depression Inventory (Beck, Steer, \& Brown, 1996), the Massachusetts Youth Screening Instrument-Second Version (MAYSI-II) (Grisso, Barnum, Fletcher, Cauffman, \& Peuschold, 2001), and the Diagnostic Interview Schedule for Children-IV (Voice DISC) (Shaffer, Fisher, Lucas, Dulcan, \& Schwab-Stone, 2000). ${ }^{3}$

3. Measure girls' strengths and assets. The gender-responsive group criticizes the assessment protocols proposed by the "what works" group as being deficiency-based, as depicting girls as pathological beings that must be fixed (Hannah-Moffat \& Shaw, 2003). They assert that it is more important to identify strengths that can be used to empower girls toward adaptive ways of coping with a sexist society (Hannah-Moffat \& Shaw, 2003). There is considerable debate as to whether these strengths, or protective factors, are just the flip side of the risk factors already measured by popular actuarial risk assessment instruments, or whether they represent a completely different set of factors (Farrington, 2000; Rutter, 1985). Nonetheless, it is recommended that these factors (e.g., self-esteem, commitment to school, positive social orientation) be included in an assessment protocol for girls, and that both sets of factors should be targeted in a treatment plan designed to reduce a girl's likelihood of problem behaviors. Possible instruments include Child and Adolescent Needs and Strengths-Juvenile Justice (CANS-JJ), the Resiliency Attitude Scale (RAS), and the Search Institute's 40 Developmental Assets ${ }^{\circledR}$ for youth. ${ }^{4}$

4. Conduct an in-depth interview with each girl upon intake. The use of objective assessment instruments does not preclude the need to get to know a girl, to listen to her story, to build a relationship with her, or to understand the circumstance that, although "not empirically related to her delinquency," impacted her life in major ways.

The above assessment protocol is consistent with the current state of knowledge regarding the risks and needs of girls. It accommodates both similarities and differences across genders and provides a basis for further research to explore, yet uncovered, risk factors associated with girls' delinquency.

\section{Building a helping alliance}

The next essential element recommended for girls' programs is the therapeutic, or helping, alliance. The therapeutic, or helping, alliance is the collaborative relationship that develops within a helping relationship. According to Horvath and Luborsky (1993), a strong helping alliance enhances a client's capacity for positive psychological change. Although implied by the "what works" responsivity principle, the helping alliance, as an essential element for working effectively with girls, is most closely aligned with the "gender-responsive" literature. This literature recognizes that many of the problems girls experience can "be traced to disconnections or violations within relationships" (Covington, 2000, p. 197). It also recognizes differences in the socialization of boys and girls that contribute to differing interpersonal styles. Girls are socialized to listen to others and value the emotional exchange that takes place within intimate relationships with others (Amaro, Blake, Schwartz, \& Flinchbaugh, 2001; Belknap, Holsinger, \& Dunn, 1997; Maccoby, 1990). Boys, on the other hand, are socialized to be achievement oriented and to prefer relationships that are characterized by well-defined roles and a directive style of interaction (Belknap et al., 1997; Maccoby, 1990). For these reasons, "gender-responsive" advocates support programs rooted in the "relational model" which sees positive change for girls being dependent on affiliation with others through trusting interpersonal relationships (Covington, 2000; Gilligan, 1982; B. J. Miller, 1986).

Consistent with the relational model, research on counseling has demonstrated that stronger alliances contribute to better therapeutic outcomes (Frieswyk, Allen, Colson, \& Coyne, 1986; Horvath \& Symonds, 1991; Stiles, Agnew-Davies, Hardy, Barkham, \& Shapiro, 1998). Despite this, recent studies suggested that little emphasis is placed on helping correctional staff develop and practice the interpersonal skills needed to establish trusting and respectful helping alliances (Reddington \& Wright-Kreisel, 2003; Taxman, 2002). Braswell (2004) claimed that helping agents within adult and juvenile corrections are often taught just the opposite through mandates to avoid getting too close to the client. He argued that these mandates undermine the human spirit and the power of the helping relationship. As a case in point, a recent study on juvenile probation officers' perceptions of the girls they serve, reported that girls were predominantly characterized as "criers, liars, and manipulators" (Gaarder, Rodriguez, \& Zatz, 2004). Although these findings are not reflective of all probation officers, they certainly make a sad statement about some of the persons who are working with these vulnerable girls. By neglecting to equip their staff with the basic communication skills needed to formulate strong relationships and failing to match girls with staff who respect and empathize with the challenges girls encounter, youth-serving agencies may be recreating the type of relationships that have played destructive roles in the lives of girls.

A high quality alliance is characterized by agreement between the change agent and the client on the goals of intervention, collaboration on the tasks required to achieve the goals, and a trusting and respectful relationship that provides a safe context for self- 
examination and personal growth (Florsheim, Shotorbani, \& GuestWarnick, 2000). Staff characteristics that have been found to be associated with strong therapeutic alliances and positive behavioral change include genuineness, acceptance, and empathy (W. R. Miller \& Rollnick, 1991; Traux \& Carkhuff, 1967). According to Rogers (1992), genuineness requires personal introspection and congruence between what you are feeling, what you believe, what you say, and what you do; acceptance is demonstrated through positive expression of feelings and respect for the client; and empathy speaks to the helping agent's ability to identify the client's core feelings and accurately communicate them back to the client.

Finally, with regard to building a helping alliance with delinquent girls, female staff may have the advantage. Male middle school counselors perceived their work with female students as more challenging due to a constant need to guard against girls' misinterpretations of their attention and motives (Rayle, 2005). Moreover, interviews with sixteen male staff who had worked with girls in nine different residential agencies indicated that they were often the target of girls' misdirected anger, and that it was not uncommon for this anger to lead to allegations of abuse (Okamoto, 2004). There is some evidence to suggest that these more guarded interactions between male staff and female consumers has impeded therapist adherence to the treatment model (Schoenwald, Letourneau, \& Halliday-Boykins, 2005) and the development of strong working alliances (Beutler, Machado, \& Neufeldt, 1994), both of which undermine the ability to achieve important counseling outcomes.

Perhaps the most important reason for ensuring that same gender matches are an option for girls is the research that suggested that people are attracted into, and most influenced by, relationships with persons who are similar to them (Bandura, 1977; Speight \& Vera, 1997). A survey of high school students indicated that same-race and samegender counseling relationships are preferred (Esters \& Ledoux, 2001), and a study of college students revealed that same gender matches were perceived as more beneficial (M. E. Johnson \& Dowling-Guyer, 1996). According to Harris and Fallot (2001), an important aspect of a trauma-informed approach to services is being aware of and honoring consumer's preference for working with the same sex staff.

Although a healthy relationship with male staff may benefit some girls, and a skilled male practitioner can be just as effective in some cases, the literature does indicate that same sex matches in counseling/ treatment is important. Any steps that can be taken to promote the development of a strong helping alliance and facilitate girls' positive change should be carefully considered.

\section{Gender-responsive cognitive-behavioral approach}

Within the context of a strong helping alliance, the use of a genderresponsive cognitive behavioral approach is recommended. The primary basis for supporting the use of cognitive-behavioral approaches with girls is the research suggesting that cognitive distortions and processing deficits contributes to a range of maladaptive behaviors among girls (see Bennett, Farrington, \& Huesman, 2005; Owens \& Chard, 2001; Simourd \& Andrews, 1994; Young, Martin, Young, \& Ting, 2001). Additionally, there is evidence to suggest that cognitive-behavioral approaches have been effective in treating depression and eating disorders among adolescent girls (Schapman-Williams, Lock, \& Couturier, 2006; Wood, Harrington, \& Moore, 1996).

In support of the responsivity principle, cognitive-behavioral approaches should be modified from those typically used with male populations in two key ways. First, as noted by Cameron and Telfer (2004), cognitive-behavioral group process should be modified to accommodate girls' need for greater support, safety, and intimacy. Many of the cognitive-behavioral programs used with male populations are confrontational in nature (e.g., programs based on Yochelson and Samenow's thinking errors) and are believed to perpetuate the type of oppression that girls frequently experience in other environ- ments (Kendall \& Pollack, 2003). Additionally, the high degree of structure associated with most cognitive-behavioral programs is believed to prohibit girls from engaging in the type of intimate communication needed to establish connections with others (Covington, 2002; Wald, Harvey, \& Hibbard, 1995). Given these concerns, it is recommended that, within any cognitive-behavioral program, extra time be allotted for girls to engage in more informal conversation, explore their feelings, and provide support to one another. In this manner, agencies can provide girls with the opportunity to connect with others without sacrificing the directive, goal-oriented approach that has been associated with successful outcomes.

Second, the content of cognitive-behavioral programs should be modified to target the types of cognitive distortions and processes that have been shown in research to be more commonly associated with girls' problem outcomes. For example:

- Females were more apt to engage in self-debasing distortions (e.g., self-blame, negative thoughts about self) and internalizing behaviors, while boys were more likely to engage in self-serving distortions (e.g., externalization of blame, rationalizations) and externalizing behaviors (Achenbach, Howell, Quay, \& Conners, 1991).

- Excessive sociotropy (i.e., concern about disapproval and acceptance) has been found to be more characteristic of girls, and has been found to lead to higher rates of depression and other problem outcomes (Kolts, Robinson, \& Tracy, 2004; McBride, Bacchiochi, \& Bagby, 2005).

- Females have been found to be more likely to engage in a ruminating, or emotion-focused coping style that makes them more prone to anxiety and depression, while boys were found to be more likely to engage in active problem solving that leads to impulsive, antisocial behavior (Hankin \& Abramson, 2001; Nolen-Hoeksema, 2001).

The content should also be modified to take advantage of protective factors that are more characteristic of girls. For example, lower rates of offending among girls have been attributed to higher levels of moral development (Mears, Ploeger, \& Warr, 1998; Silberman \& Snary, 1993), greater levels of empathy (Jolliffe \& Farrington, 2004), and the earlier acquisition of social cognitive skills (Bennett et al., 2005).

Cognitive-behavioral programs that adjust their processes and content to accommodate these and other gender differences are likely to achieve improved outcomes. It is essential that further research be conducted to uncover additional differences in the cognitive factors associated with boys and girls' delinquency, and to examine the efficacy of more gender-responsive cognitive-behavioral approaches.

\section{Promoting healthy connections}

Given the importance of relationships to girls' lives, interventions aimed at promoting healthy connections with others are viable avenues for building protection. Thus, effective programs for girls should build on the risk and protection framework, and emphasize the importance of building positive connections in the domains of family, peers, school, and community. The goal is to surround a girl with social support that insulates her from adverse circumstances that may lead to risky or antisocial behavior.

Social support is defined as "perceived or actual provisions supplied by the community, social networks, and confiding partners" (Lin, 1986, p. 18). It can be instrumental (e.g., the provision of goods or services, help with babysitting or transportation) or expressive (e.g., the provision of love and attention). Studies have shown that social support protects youth from adverse circumstances by providing them with a sense of felt security (Bretherton, 1985) and counteracting psychological and physical consequences of stress (Unger \& Wandersman, 1985; van der Kolk, 1994). In addition to providing girls with this much needed social support, promoting positive connections with others also helps to establish the social bonds, exposes girls to positive role models, and provides girls with a source of positive reinforcement for pro-social behaviors. 
Family variables are consistently identified as strong predictors of delinquent and other antisocial behaviors. Although family risk and protective factors are similar for boys and girls, there are some family factors that increase girls' vulnerability. For example, sexual abuse has been found to lead to more detrimental effects for girls later in life. Girls who were sexually abused were significantly more likely than boys to be arrested for a violent offense and to develop psychiatric disorders or substance abuse in adulthood (Bailey \& McCloskey, 2005; Herrera \& McCloskey, 2003). Additionally, although lack of emotional bonding with parents creates risk for boys, studies have found stronger correlations between lack of emotional bonding with parents and substance abuse for girls (Kakar, Friedemann, \& Peck, 2002). Thus, interventions that aim to increase family functioning by decreasing family conflict, improving communication, and increasing monitoring and supervision of girls are important to reducing girls' problem behaviors.

Schools are another context that can be particularly challenging for girls. Studies by the American Association of University Women (AAUW) $(1992,1998)$ uncovered gender bias within schools in the form of girls receiving less attention in the classroom, lower scores in math and science, and curricula that ignores or stereotypes women. Other studies found that girls experienced high rates of sexual harassment within the school setting (Fineran, 2002), and that girls' emotional safety was often threatened when participating or speaking in class (Schoenberg, Riggins, \& Salmond, 2003). These negative experiences contributed to reduced self-esteem, increased truancy, reductions in school achievement, and lower career aspirations (AAUW, 1992, 1998). School-based interventions for girls should focus primarily on helping girls feel safe by connecting them with caring adults within the school setting and by promoting academic self-efficacy.

The peer group is the most salient factor in the lives of adolescent girls. Girls who lack a cohesive friendship network experience lower self-esteem and higher rates of depression and suicide (Bearman \& Moody, 2004; Hazler \& Mellin, 2004). Relational aggression, or emotional and discreet bullying, among girls' friendship groups has been shown to interfere with the development of self-esteem and the ability to experience intimate relationships (Prinstein, Boergers, \& Vernberg, 2001). Additionally, because it often occurs in the school setting, relational aggression can lead to increased truancy and interferes with student engagement in learning (Kochenderfer \& Ladd, 1996; Olweus, 1978). On the positive side, research has found that female friendships are more likely than male friendships to act as a source of social control because of their increased intimacy and cohesiveness and because they present less pressure to offend (McCarthy, Felmlee, \& Hagan, 2004). Peer interventions that promote healthy relationships among girls may protect girls from risky and antisocial behaviors. Some promising approaches include social competency training and cognitive interventions that target negative beliefs about the self or others.

When compared to the peer groups of nondelinquent girls, the peer groups of delinquent girls were shown to involve less intimate communication, more perceived peer pressure, and more crossgender composition (Pleydon \& Schner, 2001). Reducing the negative impact of peer groups is dependent on helping the youth becoming less susceptible to peer influences or isolating the youth from negative peer influences (Giordano, Cernkovich, \& Holland, 2003). Agencies can assist girls in becoming less susceptible to peer influences by teaching them the skills needed to interact with pro-social peer groups, changing their belief systems about their peers, and connecting girls with pro-social others who provide them with a source of positive reinforcement for pro-social behavior and alter their perceptions of self. They can minimize the time spent with negative peer groups by monitoring girls' peer associations, limiting unstructured time with friends, and creating alternatives for girls to engage in pro-social activities within the community.
Three promising strategies for connecting girls with pro-social activities and others within the community include recreational programming, faith-based programming, and mentoring. Participation in sports has been found to serve as a protective factor for girls, reducing early sexual activity and teen pregnancy, substance abuse, and delinquency (K. E. Miller, Sabo, Farrell, Barnes, \& Melnick, 1998; Sabo, Farrell, Melnick, Barnes, \& Miller, 1997; Zill, Nord, \& Loomis, 1995). Girls tend to move away from sports when they reach adolescence. Culp (1998) suggested several strategies for increasing girls' involvement in recreational programming including offering girls only recreational activities, recruiting preexisting friendship groups, employing strong and caring female role models, and providing unstructured time for talking, sharing, and hanging out.

During a focus group conducted by the authors, girls cited religion, God, or spirituality as factors they needed to help them achieve their goals of continued sobriety and success in other life domains. There is some evidence of a direct relationship between "religiosity" or "spirituality" and lower rates of problem behaviors (Brown, Parks, Zimmerman, \& Phillips, 2001; Simons, Simons, \& Conger, 2004). There is more evidence, however, for the mediating effects of the social support and positive behavioral norms that organized religion provides (B. R. Johnson, 2001; B. R. Johnson, Jang, \& Li, 2001; Simons et al., 2004). For example, in a recent study, Jang and Johnson (2004) found that highly religious African Americans reported lower levels of distress that were at least partially explained by a higher sense of control and social support than that experienced by their less religious counterparts. Moreover, in a later study, Jang and Johnson (2005) found that the protective effect of religion was even stronger for women; despite higher levels of distress, highly religious women were less deviance-prone than their male counterparts. Given this research, connecting girls with a church family seems to be a viable strategy for establishing pro-social relationships and for providing girls with a much needed source of social support.

Mentoring is another viable strategy for insulating girls from adverse circumstances. A supportive relationship with a caring adult has consistently emerged in research as an important protective factor (Garmezy, 1985; Hawkins, Catalano, \& Miller, 1992; Rutter, 1985; Werner \& Smith, 1992), and given the value that girls place on relationships it seems a particularly relevant approach for girls. Taylor, Gilligan, and Sullivan (1995) found that girls involved in a caring relationship with a woman who listened to and respected their ideas and feelings reported more positive social and emotional development than girls who were not involved in this type of relationship. A study by Matthews (2004) found preliminary evidence suggesting that girls gain more benefits from mentoring than boys.

\section{Recognizing within girl differences}

Both the "what works" and gender-responsive groups have recognized the importance of understanding differences that affect the way girls relate to others and the way they respond to interventions. The most important of these differences include mental health disorders, sexual preference, and cultural backgrounds. Thus another essential element to working effectively with girls emphasizes the need to accommodate these differences in program planning and evaluation.

Although mental health disorders are not strong predictors of delinquency, they are responsivity factors that interfere with a person's amenability to treatment. Thus, prior to addressing girls' criminogenic needs, it may be necessary to treat disorders that undermine potential treatment gains. Two of the most prevalent mental health disorders among delinquent girls include depression and posttraumatic stress disorder (PTSD). During adolescence girls are two times more likely to be depressed than boys (Obeidallah \& Earls, 1999). It is speculated that this higher prevalence stems from girls' greater exposure to stressful life events and to an emotion-focused 
coping style that is more common among girls (Hazler \& Mellin, 2004). Depression is difficult to distinguish from typical adolescent behaviors (e.g., intensity of emotions; increased need for sleep; irritability); thus, it is often left undiagnosed and untreated, opening the door for later problem behaviors. Depression has been found to contribute to problems with academic functioning and interpersonal relationships, both of which increase a youth's risk of delinquency (Obeidallah \& Earls, 1999). Often girls' entry into substance abuse is preceded by depression by as much as five years, pointing to the importance of early diagnosis and treatment. Cognitive therapies are among the most effective types of treatment for adolescent girls experiencing depression (Clarke \& Rohde, 1999; Wood et al., 1996).

Studies showed that PTSD is one of the most common disorders among offenders and/or incarcerated youth. Studies suggested that the rate of PTSD among girls was not only higher than in the general population, but also higher than adolescent male offenders (Cauffman, Feldman, \& Waterman, 1998). As with depression, the early identification and treatment of PTSD may prevent later problem behaviors. For example, many studies have suggested that girls often use substances to mediate the effects of PTSD and sexual abuse (Epstein, Saunders, \& Kilpatrick, 1998). Despite the apparent link between PTSD and antisocial behaviors, there is a debate as to whether or not treatment for delinquent youth should address past victimization. Many juvenile justice professionals have argued that a focus on the youth's victimization provides them with excuses for their delinquent behavior. Mental health professionals have argued that failure to address past victimization and the resulting PTSD will contribute to diminished success in treatment.

Clearly, juvenile justice professionals working with girls should receive training on the symptoms, effects, and treatment of depression and PTSD. It is equally important, however, for them to know their professional limitations and make appropriate referrals to mental health professionals. To make appropriate referrals, juvenile justice professionals should become familiar with the protocols and treatment approaches used by community resources. Juvenile justice professionals can serve as advocates for girls' mental health services by documenting the prevalence of disorders among their offender population and by being familiar with research on effective programming.

Another difference that is important to understand when working with girls is their sexual orientation. Studies have shown that lesbian, bisexual, and transgender girls were at greater risk for delinquency and other antisocial behaviors (see Anhalt \& Morris, 1998). For example, 25 to 35 percent of lesbians were found to have serious problems with alcohol and drugs compared to 10 percent in the general population; 20 to 40 percent of runaway and street youth were found to be gay or lesbian; and lesbians were found to be two to four times more likely to attempt suicide. These problems are believed to stem from the silence imposed on these girls that diminishes their ability to develop a friendship network and seek social support (Cato \& Canetto, 2003; Udry \& Chantala, 2003). Juvenile justice agencies can enhance services for lesbian, bisexual, and transgender girls by avoiding language and assumptions that present alternative sexual orientations as pathological states, providing visible role models, being familiar with resources for girls with alternative sexual orientations, and matching them to staff who view their lifestyles as valid and are comfortable with their own sexuality.

Finally, race, ethnicity, and class differences are also important to acknowledge in girls' programming. The gender-responsive group has emphasized the need to understand how gender, race, and class intersect to create worldviews that influence girls' relationships with others (MacDonald \& Chesney-Lind, 2001). Research on counseling and psychotherapy has demonstrated that a failure to understand and value cultural differences can impede the development of rapport and strong alliances that are needed for effective helping relationships (Sue \& Sue, 1999). According to Parrott (1997), a lack of cultural knowledge and sensitivity on the part of service providers leads to underutilization of and early termination from services among minority groups.

Minority girls have been overrepresented at each stage in the juvenile justice process (Bond-Maupin, Maupin, \& Leisenring, 2002; Poe-Yamagata \& Jones, 2000; Schaffner, 2006; Snyder \& Sickmund, 2006). According to Belknap (2001) and others, because the behavior of Black girls conflicts with dominant societal expectations for girls, they are more likely to get in trouble and to be punished more harshly. Chung and Bernak (2002) assert that understanding this, and other ways that racism, sexism, and classism affect the lives of clients, is essential to expressing the cultural empathy required to build strong helping alliances.

Another cultural dimension that is important to consider when working with girls is social class. According to a study conducted by Payne, DeVol, and Druessi Smith (2001), living in poverty affected the way people managed their lives and related to others. For example, persons who lived in poverty were found more likely to be presentoriented, believe in fate as the factor that will determine their destiny, and view education as having little relevance to their lives. Their behavior was driven by their daily fight for survival, and planning for the future seemed futile. This overriding orientation for the present interferes with the development of procedural memory, which in turn, inhibits the ability to follow directions and contributes to a lack of planning and organizational skills. A failure to understand and acknowledge these class differences will result in interventions and case plans that seem disconnected from reality.

Although mental health, sexual orientation, and cultural differences among girls are particularly important to consider in delinquency programming, other within girl differences cannot be overlooked. Throughout this article, behavioral tendencies and characteristics that are more common among girls than boys have been highlighted; these tendencies and characteristics, however, should not be used as the basis for strict prescriptive programming. Such an approach would reflect the very type of gender stereotyping that is important to avoid. Continued movement toward evidencebased, gender-responsive programming is dependent on future research that examines how within girl differences impact girls' responses to various types of interventions.

\section{Conclusion}

This article started with a discussion of impediments to the development of effective girls' programming within the juvenile justice system. It then turned, like many articles before it, to recommendations for program elements deemed essential to promoting the positive growth of delinquent girls. What is the difference between the type of gender-responsive programming proposed herein and the genderstereotyped programming that has been criticized? The difference is that the former focuses on substantive gender differences that have been found, through research, to impact behavior and response to treatment, while the latter focuses on superficial preferences or tendencies that have no basis in counseling or delinquency research or theory. For example, a program that targets the more emotional, and frequently maladaptive, coping style of delinquent girls has a better likelihood of promoting long-term behavioral change than one that simply appeals to girls' aesthetic or domestic preferences.

In sum, this article was written with two objectives in mind. First, it was hoped that those who read the article would recognize the links between these five elements and available research and theory on working effectively with girls. Although the research is limited, there is a sufficient theoretical and conceptual basis to begin developing substantive programs that meet the needs of girls in the juvenile justice system. Second, the article described simple, concrete ways to transfer this knowledge into practice. None of the recommended elements require a significant investment of financial resources; they do, however, require a significant investment of human resources, 
and a commitment to developing programs "as if gender mattered" (Chesney-Lind, 2001, p. 38).

Given the lack of investment in the evaluation of girls' programming, agencies cannot afford to wait for a gender-specific empirical basis. What they can do is develop programs that integrate the "what works" and the "gender-responsive" literatures in a way that reflects the greatest contributions of each. That is, agencies can use inductive reasoning to build on the empirical basis for effective programming that emanates from the "what works" literature, while also grounding program design in the "gender-responsive" literature that reflects a stronger theoretical basis and conceptual understanding of girls' unique experiences and needs. A very important next step involves working with agencies to implement the recommended elements and test their effectiveness to further clarify "what works" for girls.

\section{Notes}

1. The authors recognize that these proposed categories of literature may be overly simplistic, as there are scholars who have contributed to both the "gender-responsive" and "what works" literatures. Moreover, the authors do not mean to imply that the identified scholars are in agreement with all that is written within these broad categories of literature.

2. For a detailed discussion of the substantive differences between the "genderresponsive" and "what works" literatures, see Hubbard and Matthews (2008).

3. For a complete listing of suitable instruments, see Grisso and Underwood (2004).

4. Ibid.

\section{References}

Achenbach, T. M., Howell, C. T., Quay, H. C., \& Conners, C. K. (1991). National survey of problems and competencies among four- to sixteen-year-olds: Parents' reports for normative and clinical samples. Monographs of the Society for Research in Child Development, 56, 5-120.

Amaro, H., Blake, S., Schwartz, P., \& Flinchbaugh, L. (2001). Developing theory-based substance abuse prevention programs for young adolescent girls. Journal of Early Adolescence, 31, 256-293.

American Association of University Women. (1992). How schools shortchange girls: The AAUW report. Washington, DC: American Association of University Women Educational Foundation.

American Association of University Women. (1998). Gender gaps: Where schools fail our children. Washington, DC: American Association of University Women Educational Foundation.

Andrews, D. A., \& Bonta, J. (1999). The psychology of criminal conduct. Cincinnati, OH: Anderson.

Andrews, D. A., Bonta, J. D., \& Hoge, R. D. (1990). Classification for effective rehabilitation: Rediscovering psychology. Criminal Justice and Behavior, 17, 19-52.

Andrews, D. A., Zinger, I., Bonta, J. D., Gendreau, P., \& Cullen, F. T. (1990). Does correctional treatment work? A psychologically informed meta-analysis. Criminology, 28, 369-404.

Anhalt, K., \& Morris, T. L. (1998). Developmental and adjustment issues of gay, lesbian, and bisexual adolescents: A review of the empirical literature. Clinical Child and Family Psychology Review, 1, 215-130.

Bailey, J., \& McCloskey, L. (2005). Pathways to adolescent substance abuse among sexually abused girls. Journal of Abnormal Child Psychology, 33, 39-53.

Bandura, A. (1977). Social learning theory (1st ed.). Upper Saddle River, NJ: Pearson Professional.

Bearman, P. S., \& Moody, J. (2004). Suicide and friendships among American adolescents. American Journal of Public Health, 94, 89-95.

Beck, A. T., Steer, R. A., \& Brown, G. K. (1996). Beck depression inventory. San Antonio, TX: Harcourt Assessment.

Belknap, J. (2001). The invisible woman: Gender, crime, and justice. Cincinnati, $\mathrm{OH}$ : Wadsworth.

Belknap, J., \& Holsinger, K. (1998). An overview of delinquent girls: How theory and practice have failed and the need for innovative changes. In R. Zaplin (Ed.), Female offenders: Critical perspectives and effective intervention. Gaithersburg, MD: Aspen.

Belknap, J., Holsinger, K., \& Dunn, M. (1997). Moving toward juvenile justice and youthserving systems that address the distinct experiences of the adolescent female: A report to the governor. Columbus, $\mathrm{OH}$ : Office of Criminal Justice Services.

Bennett, S., Farrington, D. P., \& Huesman, L. R. (2005). Explaining gender differences in crime and violence: The importance of social cognitive skills. Aggression and Violent Behavior, 10, 263-288.

Beutler, L. E., Machado, P. P., \& Neufeldt, S. (1994). Therapist variables. In A. E. Bergin \& S. L. Garfield (Eds.), Handbook of psychotherapy and behavior change (4th ed., pp. 259-269). New York: Wiley.

Bloom, B. (2000). Beyond recidivism: Perspectives on evaluation of programs for female offenders in community corrections. In M. McMahon (Ed.), Assessment to assistance: Programs for women in community corrections. Lanham, MD: American Correctional Association.
Bloom, B., Owen, B., \& Covington, S. (2003). Gender-responsive strategies: Research, practice, and guiding principles for women offenders (NIC No. 018017). Washington, DC: National Institute of Corrections.

Bond-Maupin, L., Maupin, J., \& Leisenring, A. (2002). Girls' delinquency and the justice implications of intake workers' perspectives. Women and Criminal Justice, 13, 51-77.

Braswell, M. (2004). The function of correctional counseling and treatment. In P. Van Voorhis, M. Braswell, \& D. Lester (Eds.), Correctional counseling and rehabilitation (5th ed.). Cincinnati, OH: Anderson.

Bretherton, I. (1985). Attachment theory: Retrospect and prospect. In I. Bretherton \& E. Waters (Eds.), Growing points of attachment theory and research. Chicago: University of Chicago Press.

Brown, T., Parks, G., Zimmerman, R., \& Phillips, C. (2001). The role of religion in predicting adolescent alcohol use and problem drinking. Journal of Studies on Alcohol, 62, 696-705.

Brumbaugh, S., \& Hardison, J. (2006, July). Issues in assessing risk with delinquent girls Paper presented at the annual meeting of the National Institute of Justice Washington, DC.

Cameron, H., \& Telfer, J. (2004). Cognitive-behavioural group work: Its application to specific offender groups. Howard Journal of Criminal Justice, 43, 47-64.

Cato, J., \& Canetto, S. (2003). Attitudes and beliefs about suicidal behavior when coming out is the precipitant of the suicidal behavior. Sex Roles, 49, 497-505.

Cauffman, E., Feldman, S., \& Waterman, J. (1998). Posttraumatic stress disorder among female juvenile offenders. Journal of the American Academy of Child and Adolescent Psychiatry, 37, 1209-1216.

Chesney-Lind, M. (1997). The female offender: Girls, women, and crime. Thousand Oaks, CA: Sage.

Chesney-Lind, M. (2000). What to do about girls? Thinking about programs for young women. In M. McMahon (Ed.), Assessment to assistance: Programs for women in community corrections (pp. 139-170). Lanham, MD: American Correctional Association.

Chesney-Lind, M. (2001, February). What about the girls? Delinquency programming as if gender mattered. Corrections Today, 38-45.

Chesney-Lind, M. (2003, October). Gender and justice: What about girls. Paper presented at the National Girls' Initiative Symposium, Washington, DC.

Chung, R. C., \& Bernak, F. (2002). The relationship of culture and empathy in crosscultural counseling. Journal of Counseling and Development, 80, 154-159.

Clarke, G. N., \& Rohde, P. (1999). Cognitive-behavioral treatment of adolescent depression: Efficacy of acute group treatment. Journal of the American Academy of Child and Adolescent Psychiatry, 38, 272-280.

Covington, S. (2000). Helping women recover: Gender-specific treatment for substance abuse in community corrections. In M. McMahon (Ed.), Assessment to assistance: Programs for women in community corrections (pp. 139-170). Lanham, MD American Correctional Association.

Covington, S. (2002). Helping women recover: Creating gender-responsive treatment. In S. L. Ashenberg \& S. Brown (Eds.), The handbook of addiction treatment (pp. 52-72). San Francisco: Jossey-Bass.

Covington, S., \& Bloom, B. (1999, November). Gender-responsive programming and evaluation for females in the criminal justice system: A shift from what works? To what is the work? Paper presented at the fifty-first annual meeting of the American Society of Criminology, Toronto, Ontario, Canada.

Covington, S., \& Bloom, B. (2003). Gendered justice: Women in the criminal justice system. In B. Bloom (Ed.), Gendered justice: Addressing female offenders (pp. 3-24) Durham, NC: Carolina Academic Press.

Cullen, F. T., \& Gendreau, P. (2000). Assessing correctional rehabilitation: Policy, practice, and prospects. In J. Horney, J. Martin, D. L. MacKenzie, R. Peterson, \& D Rosenbaum (Eds.), Policies, processes, and decisions of the criminal justice system: Criminal justice 2000 (Vol. 3, pp. 109-175). Washington, DC: U.S. Department of Justice, National Institute of Justice.

Culp, R. H. (1998). Adolescent girls and outdoor recreation: A case study examining constraints and effective programming. Journal of Leisure Research, 30, 356-380.

Epstein, J., Saunders, B., \& Kilpatrick, D. (1998). PTSD as a mediator between childhood rape and alcohol use in adult women. Child Abuse and Neglect, 22, 223-234.

Esters, I., \& Ledoux, C. (2001). At-risk high school students' preferences for counselor characteristics. Professional School Counseling, 4, 165-170.

Farrington, D. (2000). Explaining and preventing crime: The globalization of knowledge-the American Society of Criminology 1999 presidential address. Criminology, 38, 1-24.

Fineran, S. (2002). Adolescents at work: Gender issues and sexual harassment. Violence Against Women, 8, 953-967.

Flores, A. W., Travis, L. F., \& Latessa, E. J. (2004). Case classification for juvenile corrections: An assessment of the Youth Level of Service/Case Management Inventory (YLS/CMI), final report (NCJ 204005). Washington, DC: National Institute of Justice.

Florsheim, P., Shotorbani, S., \& Guest-Warnick, G. (2000). Role of the working alliance in the treament of delinquent boys in community based programs. Journal of Clinical Child Psychology, 29, 94-107.

Frieswyk, S., Allen, J., Colson, D., \& Coyne, L. (1986). Therapeutic alliance: Its place as a process and outcome variable in dynamic psychotherapy research. Journal of Consulting and Clinical Psychology, 5, 483-489.

Gaarder, E., Rodriguez, N., \& Zatz, M. (2004). Criers, liars, and manipulators: Probation officers' views of girls. Justice Quarterly, 21, 547-578.

Garmezy, N. (1985). Stress resistant children: The search for protective factors. In J. E Stevenson (Ed.), Recent research in developmental psychopathology. Oxford, England: Pergamon.

Gilligan, C. (1982). In a different voice. Cambridge, MA: Harvard University Press

Giordano, P., Cernkovich, S., \& Holland, D. (2003). Changes in friendship relations over the life course: Implications for desistance from crime. Criminology, 41, 293-327. 
Goodkind, S. (2005). Gender-specific services in the juvenile justice system: A critical examination. Affilia, 20, 52-70.

Gottfredson, S. (1987). Prediction: An overview of selected methodological issues. In D. M. Gottfredson \& M. Tonry (Eds.), Prediction and classification: Criminal justice decision making (pp. 21-51). Chicago: University of Chicago Press.

Grisso, T., Barnum, R., Fletcher, K. E., Cauffman, E., \& Peuschold, D. (2001). Massachusetts Youth Screen Instrument for mental health needs of juvenile justice youths. Journal of the American Academy of Child and Adolescent Psychiatry, 40, 541-549.

Grisso, T., \& Underwood, L. (2004). Screening and assessing mental health and substance use disorders among youth in the juvenile justice system: A resource guide for practitioners (NCJ 204956). Washington, DC: Office of Juvenile Justice and Delinquency Prevention.

Hankin, B. L., \& Abramson, L. Y. (2001). Development of gender differences in depression: An elaborated cognitive vulnerability-transactional stress theory. Psychological Bulletin, 127, 773-796.

Hannah-Moffat, K. (1999). Moral agent or actuarial subject: Risk and Canadian women's imprisonment. Theoretical Criminology, 3, 71-94.

Hannah-Moffat, K., \& Shaw, M. (2003). The meaning of 'risk' in women's prisons: critique. In B. Bloom (Ed.), Gendered justice: Addressing female offenders (pp. 69-96). Durham, NC: Carolina Academic Press.

Harris, M., \& Fallot, R. D. (2001). Envisioning a trauma-informed service system: A vital paradigm shift. In M. Harris \& R. D. Fallot (Eds.), Using trauma theory to design service systems (pp. 3-22). San Francisco: Jossey-Bass.

Hartman, S. (2006, November 10). California sends delinquents to finishing schoo [Television series episode]. In CBS (Producer), CBS evening news. New York: CBS Broadcasting.

Hawkins, D. J., Catalano, R. F., \& Miller, J. M. (1992). Risk and protective factors for alcoho and other drug problems in adolescence and early childhood: Implications for substance abuse prevention. Psychological Bulletin, 112, 64-105.

Hazler, R. J., \& Mellin, E. A. (2004). The developmental origins and treatment needs of female adolescents with depression. Journal of Counseling and Development, 82 18-24.

Herrera, V., \& McCloskey, L. (2003). Sexual abuse, family violence, and female delinquency: Findings from a longitudinal study. Violence and Victims, 18, 319-334.

Hoge, R., \& Andrews, D. (2002). Youth Level of Service/Case Management Inventory (YLSI/CMI): Users' manual. North Tonawanda, NY: Multi-Health Systems.

Horvath, A., \& Luborsky, L. (1993). The role of the therapeutic alliance in psychotherapy. Journal of Consulting and Clinical Psychology, 61, 561-573.

Horvath, A. O., \& Symonds, D. B. (1991). Relationship between working alliance and outcome in psychotherapy: A meta-analysis. Journal of Counseling Psychology, 38 139-149.

Hubbard, D. J., \& Matthews, B. (2008). Reconciling the differences between the "genderresponsive" and the "what works" literatures to improve services for girls. Crime and Delinquency, 54, 225-258.

Ilacqua, G. E., Coulson, G. E., Lombardo, D., \& Nutbrown, V. (1999). Predictive validity of the Young Offender Level of Service Inventory for criminal recidivism of male and female young offenders. Psychological Reports, 84,1214-1218.

Jang, S. J., \& Johnson, B. R. (2004). Explaining religious effects on distress among African Americans. Journal for the Scientific Study of Religions, 43, 239-260.

Jang, S. J., \& Johnson, B. R. (2005). Gender, religiosity, and reactions to strain among African Americans. Sociological Quarterly, 46, 323-357.

Johnson, B. R. (2001). Reviewing and clarifying the role of religion in reducing crime and delinquency. Federal Probation, 65, 49-53.

Johnson, B. R., Jang, S. J., \& Li, S. D. (2001). Does adolescent religious commitment matter? A reexamination of the effects of religiosity on delinquency. Journal of Research Crime and Delinquency, 38, 22-43.

Johnson, M. E., \& Dowling-Guyer, S. (1996). Effects of inclusive versus exclusive language on evaluation of the counselor. Sex Roles, 34, 407-416.

Jolliffe, D., \& Farrington, D. P. (2004). Empathy and offending: A systematic review and meta-analysis. Aggression and Violent Behavior, 9, 441-476.

Jones, P. (1996). Risk prediction in criminal justice. In A. Harland (Ed.), Choosing correctional options that work: Defining the demand and evaluating the supply. Thousand Oaks, CA: Sage.

Kakar, S., Friedemann, M., \& Peck, L. (2002). Girls in detention: The results of focus group discussion interviews and official records review. Journal of Contemporary Criminal Justice, 18, 57-73.

Kendall, K., \& Pollack, S. (2003). Cognitive behavioralism in women's prisons: A critical analysis of therapeutic assumptions and practices. In B. Bloom (Ed.), Gendered justice: Addressing female offenders. Durham, NC: Carolina Academic Press.

Kochenderfer, B., \& Ladd, G. (1996). Peer victimization: Cause or consequence of school maladjustment? Child Development, 67, 1305-1317.

Kolts, R. L., Robinson, A. M., \& Tracy, J. J. (2004). The relationship of sociotropy and autonomy to posttraumatic cognitions and PTSD symptomatolgy in trauma survivors. Journal of Clinical Psychology, 60, 53-63.

Lahm, K. F. (2000). Equal or equitable: An exploration of education and vocational programs available for male and female offenders. Federal Probation, 64, 39-46.

Latessa, E., Cullen, F., \& Gendreau, P. (2002). Beyond correctional quackery: Professionalism and the possibility of effective treatment. Federal Probation, 66, 43-49.

Levene, K., Augimeri, L., Pepler, D., Walsh, N., Webster, C., \& Koegl, C. (2001). Early assessment risk list for girls: EARL-21G version 1 (Consultation ed.). Toronto, Ontario, Canada: Earlscourt Child and Family Centre.

Lin, N. (1986). Conceptualizing social support. In N. Lin, A. Dean, \& W. Edsel (Eds.), Social support, life events, and depression Orlando, FL: Academic Press.

Lipsey, M. W., \& Cullen, F. T. (2007). The effectiveness of correctional rehabilitation: A review of systematic reviews [Electronic version]. Annual Review of Law and Socia Science, 3.
Lipsey, M. W., \& Wilson, D. (1998). Effective intervention for serious juvenile offenders: A synthesis of research. In R. Loeber \& D. P. Farrington (Eds.), Serious and violent juvenile offenders: Risk factors and successful interventions. Thousand Oaks, CA: Sage.

Lowenkamp, C. T., \& Latessa, E. J. (2002). Evaluation of Ohio's community based correctional facilities and halfway house programs [Tech. Rep.]. Cincinnati, $\mathrm{OH}$ : University of Cincinnati.

Lowenkamp, C. T., \& Latessa, E. J. (2004). Understanding the risk principle: How and why correctional interventions can harm low-risk offenders. Topics in Community Corrections, 3-7.

Maccoby, E. (1990). Gender and relationships: A developmental account. American Psychologist, 45, 513-520.

MacDonald, J., \& Chesney-Lind, M. (2001). Gender bias and juvenile justice revisited: A multiyear analysis. Crime and Delinquency, 47, 173-195.

Matthews, B. (2004). Enhancing the protective capacity of mentoring relationships: Strengthening the social bond. Unpublished doctoral dissertation, University of Cincinnati, Cincinnati, $\mathrm{OH}$

McBride, C., Bacchiochi, J. R., \& Bagby, M. (2005). Gender differences in the manifestation of sociotropy and autonomy personality traits. Personality and Individual Differences, 38, 129-136.

McCarthy, B., Felmlee, D., \& Hagan, J. (2004). Girl friends are better: Gender, friends, and crime among school and street youth. Criminology, 42, 805-835.

Mears, D., Ploeger, M., \& Warr, M. (1998). Explaining the gender gap in delinquency: Peer influence and moral evaluations of behavior. Journal of Research in Crime and Delinquency, 35, 251-266.

Miller, B. J. (1986). Toward a new psychology of women. Boston: Beacon Press.

Miller, K. E., Sabo, D. F., Farrell, M. P., Barnes, G. M., \& Melnick, M. J. (1998). Athletic participation and sexual behavior in adolescents: The different worlds of boys and girls. Journal of Health and Social Behavior, 39, 108-123.

Miller, W. R., \& Rollnick, S. (1991). Motivational interviewing: Preparing people to change addictive behavior. New York: The Guilford Press.

Morash, M. R., Haarr, R., \& Rucker, L. (1994). A comparison of programs for women and men in United States prisons in the 1980s. Crime and Delinquency, 2, 197-221.

Nolen-Hoeksema, S. (2001). Gender differences in depression. Current Directions in Psychological Science, 10, 173-176.

Obeidallah, D. A., \& Earls, F. J. (1999, July). Adolescent girls: The role of depression in the development of delinquency. Washington, DC: National Institute of Justice.

Okamoto, S. K. (2004). Relational aggression of girls in treatment: A challenge for male practitioners. Residential Treatment for Children and Youth, 21, 89-100.

Olweus, D. (1978). Aggression in the schools: Bullies and whipping boys. Washington, DC: Hemisphere.

Owens, G., \& Chard, K. (2001). Cognitive distortions among women reporting childhood sexual abuse. Journal of Interpersonal Violence, 16, 178-191.

Palmer, T. (1995, January). Programmatic and nonprogrammatic aspects of successful intervention: New directions for research. Crime and Delinquency, 42, 100-131.

Parrott, L. (1997). Counseling and psychotherapy. New York: McGraw-Hill.

Payne, R. K., DeVol, P., \& Druessi Smith, T. (2001). Bridges out of poverty: Strategies for professionals and communities. Highlands, TX: aha! Process, Inc.

Pleydon, A., \& Schner, J. (2001). Female adolescent friendship and delinquent behavior. Adolescence, 36, 189-205.

Poe-Yamagata, E., \& Jones, M. (2000). And justice for some: Differential treatment of minority youth in the justice system. Washington, DC: Building Blocks for Youth.

Prinstein, M., Boergers, L., \& Vernberg, E. (2001). Overt and relational aggression in adolescents: Social-psychological adjustment of aggressors and victims. Journal of Clinical Child Psychology, 30, 479-491.

Rafter, N. (1995). Partial justice: Women, prisons, and social control (2nd ed.). Boston: Northeastern University Press.

Rayle, A. D. (2005). Cross-gender interactions in middle school counselor-student working alliances: Challenges and recommendations. Professional School Counseling, 9, 152-155

Reddington, F., \& Wright-Kreisel, B. (2003). Basic fundamental skills training for juvenile probation officers-Results of a nationwide survey of curriculum content. Federal Probation, 67, 41-45.

Rogers, C. (1992). The necessary and sufficient conditions of therapeutic personality change. Journal of Consulting and Clinical Psychology, 60, 827-833.

Rutter, M. (1985). Resilience in the face of adversity: Protective factors and resistance to psychiatric disorder. British Journal of Psychiatry, 147, 598-611.

Sabo, D.F., Farrell, M.P., Melnick, M.J., Barnes, G.M., \& Miller, K.E. (1997, August). High school athletic participation, sexual behavior and adolescent pregnancy: A preliminary analysis. Paper presented at the ninety-seventh annual meeting of the American Sociological Association, Toronto, Ontario, Canada.

Schaffner, L. (2006). Girls in trouble with the law. Piscataway, NJ: Rutgers University Press. Schapman-Williams, A. M., Lock, J., \& Couturier, J. (2006). Cognitive-behavioral therapy for adolescents with binge eating syndromes: A case series. International Journal of Eating Disorders, 39, 252-255.

Schoenberg, J., Riggins, T., \& Salmond, K. (2003). Feeling safe: What girls say. New York: Girl Scouts of the USA.

Schoenwald, S. K., Letourneau, E. J., \& Halliday-Boykins, C. (2005). Predicting therapist adherence to a transported family-based treatment for youth. Journal of Clinical Child and Adolescent Psychology, 34, 658-670.

Schwalbe, C., Fraser, M., Day, S., \& Arnold, E. M. (2004). North Carolina assessment of risk (NCAR): Reliability and predictive validity with juvenile offenders. Journal of Offender Rehabilitation, 40, 1-22.

Shaffer, D. M., Fisher, P. W., Lucas, C., Dulcan, M. K., \& Schwab-Stone, M. E. (2000). NIMH Diagnostic Interview Schedule for Children version IV (NIMH DISC-IV): Description, differences from previous versions, and reliability of some common diagnoses. Journal of American Academy of Child and Adolescent Psychiatry, 39, 28-38. 
Sherman, L. W., Gottfredson, D. C., MacKenzie, D. L., Eck, J., Reuter, P., \& Bushway, S. (Eds.). (1997). Preventing crime: What works, what doesn't, what's promising. Washington, DC: National Institute of Justice.

Silberman, M. A., \& Snary, J. (1993). Gender differences in moral development during early adolescence: The contribution of sex-related variations in maturation. Current Psychology, 12, 163-172.

Simons, L., Simons, R., \& Conger, R. (2004). Identifying the mechanisms whereby family religiosity influences the probability of adolescent antisocial behavior. Journal of Comparative Family Studies, 35, 547-563.

Simourd, D. J., \& Andrews, D. L. (1994). Correlates of delinquency: A look at gender differences. Ottawa, Ontario, Canada: Carleton University, Department of Psychology.

Snyder, H., \& Sickmund, M. (2006). Juvenile offenders and victims: 2006 national report. Washington, DC: Office of Juvenile Justice and Delinquency Prevention.

Speight, S. L., \& Vera, E. M. (1997). Similarity and difference in multicultural counseling: Considering the attraction and repulsion hypotheses. The Counseling Psychologist. 25, 280-298.

Steffensmeier, S., Schwartz, J., \& Zhong, H. (2005). An assessment of recent trends in girls' violence using diverse longitudinal sources: Is the gender gap closing? Criminology, 43, 355-405.

Stiles, W. B., Agnew-Davies, R., Hardy, G. E., Barkham, M., \& Shapiro, D. A. (1998). Relations of the alliance with psychotherapy outcome: Findings in the second Sheffield Psychotherapy Project. Journal of Consulting and Clinical Psychology, 66, 791-802.

Sue, D. W., \& Sue, D. (1999). Counseling the culturally different: Theory and practice (3rd ed.). New York: Wiley.

Taxman, F. (2002). Supervision-exploring the dimensions of effectiveness. Federal Probation, 66, 14-27.

Taylor, J. M., Gilligan, C., \& Sullivan, A. M. (1995). Between voice and silence: Women, girls, race and relationship. Boston: Harvard University Press.
Traux, C. B., \& Carkhuff, R. R. (1967). Toward effective counseling and psychotherapy. Chicago: Aldine.

Udry, J., \& Chantala, K. (2003). Missing school dropouts in surveys does not risk estimates. Social Science Research, 32, 294-311.

Unger, D. G., \& Wandersman, A. (1985). The importance of neighbors: The social cognitive, and affective components of neighboring. American Journal of Community Psychology, 13, 139-169.

van der Kolk, B. A. (1994). Trauma and development in children. Albany: New York State Department of Mental Health, State-wide Grand Rounds.

Wald, R., Harvey, S. M., \& Hibbard, J. (1995). A treatment model for women substance users. International Journal of the Addictions, 30, 881-888.

Ward, T., Melser, J., \& Yates, P. M. (2007). Reconstructing the risk need responsivity model: A theoretical elaboration and evaluation. Aggression and Violent Behavior, $12,208-228$.

Werner, E. E., \& Smith, R. S. (1992). Overcoming the odds: High risk children from birth to adulthood. New York: Cornell University.

Wood, A., Harrington, R., \& Moore, A. (1996). Controlled trial of a brief cognitive behavioral intervention in adolescent patients with depressive disorders. Journal of Child Psychology and Psychiatry, 87, 737-746.

Young, T. M., Martin, S. S., Young, M. E., \& Ting, L. (2001). Internal poverty and teen pregnancy. Adolescence, 36, 289-305.

Zahn, M. (2006, July). Girls Study Group: Preliminary findings. Paper presented at the annual meeting of the National Institute of Justice, Washington, DC.

Zill, N., Nord, C., \& Loomis, L. (1995). Adolescent time use, risky behavior, and outcomes: An analysis of national data. Rockville, MD: Westat. 